\title{
COMPOSIÇÃO E QUALIDADE DO LEITE EM DIFERENTES TIPOS E TEMPOS DE RESFRIAMENTO
}

\author{
Ilton Isandro Eckstein ${ }^{1}$, Magali Soares dos Santos Pozza², Claudio Yuji Tsutsumi ${ }^{3}$, \\ Paulo Cesar Pozza ${ }^{2}$, Mayara Andressa Sabedot ${ }^{4}$, Jaqueline Rocha Wobeto ${ }^{3}$ \\ 1 EMATER \\ 2 UEM \\ 3 UNIOESTE \\ ${ }^{4}$ UFBA \\ Correspondência: Ilton Isandro Eckstein: eckstein@zootecnista.com.br
}

RESUMO: O Ministério da Agricultura, Pecuária e Abastecimento estabelece métodos de refrigeração, além de valores mínimos e máximos de qualidade do leite. Assim, o objetivo do trabalho foi avaliar amostras de leite cru, em diferentes tipos de refrigeração (tanque de expansão, tanque de imersão, freezer) e tempos de armazenamento (2, 12 e 24 horas). Foram coletadas 90 amostras de leite, e estas foram avaliadas em relação à sua composição, contagem de células somáticas (CCS) e contagem bacteriana total (CBT). Ao observar os resultados médios dos componentes do leite verificou-se que estes estavam dentro dos padrões exigidos pela IN 62, porém para a CCS e a CBT apenas 41,11 e $50 \%$, respectivamente das amostras se encontravam dentro dos padrões. Em relação aos tipos de refrigeração houve diferença significativa $(p<0,05)$ para a CCS e CBT, e para os tempos de armazenamento houve diferença significativa apenas para a CBT, não diferindo para a composição e CCS. Entre os métodos utilizados para limpeza do tanque de armazenamento, não houve diferenças, porém os métodos de limpeza nos equipamentos de ordenha diferiram entre si. Conclui-se que a qualidade do leite sofreu interferência dos tipos de refrigeração e tempos de armazenamento, como dos métodos utilizados para a higiene dos equipamentos de ordenha.

Palavras-chave: armazenamento; higiene; refrigeração; tanque

\section{COMPOSITION AND QUALITY OF THE MILK IN DIFFERENT TYPES AND TIMES OF COOLING}

\begin{abstract}
The Ministry of Agriculture, Livestock and Supply provides cooling methods, and minimum and maximum values for milk quality. Thus, the objective of this study was to evaluate raw milk samples, in different types of refrigeration (expansion tank, immersion tank and freezer) and storage times (2, 12 and 24 hours). It was collected 90 samples of milk, and these were evaluated in relation to the composition, somatic cell count (SCC) and total bacterial count (TBC). When was observed the average results of milk components was found that these were on the limits required by the IN 62, but for SCC and TBC only 41.11 and $50 \%$, respectively of the samples were on the standards. Regarding the types of refrigeration, had significant difference $(p<0.05)$ for SCC and TBC, and fot the storage times, had significant difference only for the TBC did not differ for the composition and SCC. Between the methods used for cleaning the storage tank, there was no difference. However the methods for cleaning the milking equipment differ. It was concluded that the quality of milk suffered interference of the types of refrigeration and storage times, like the methods used for the hygiene of the milking equipment.
\end{abstract}

Key Words: hygiene; refrigeration; storage; tank 


\section{INTRODUÇÃO}

O leite é fonte de macro e micronutrientes, 0 que o torna um excelente meio para o desenvolvimento de microrganismos deterioradores, sendo necessários métodos de conservação, como refrigeração (Minim et al., 2002).

A composição do leite, assim como a contagem de células somáticas (CCS), são de extrema importância quando se avalia a qualidade do leite (Fonseca \& Santos, 2000). Estes dados, aliados à contagem bacteriana total (CBT) servem como índices básicos para o controle desta matéria-prima em toda a cadeia do leite, incluindo produtores, indústria e consumidores. $\mathrm{O}$ estudo dos fatores que influenciam a composição do leite passa a ser de grande relevância para minimizar as perdas e aumentar a rentabilidade da propriedade e da indústria (Brito et al., 1998).

Com a entrada em vigor da Instrução Normativa 51/2002 - MAPA, os produtores de leite tiveram que se adequar à esta, instalando tanques de refrigeração nas propriedades rurais, o que implicou em custos de implantação e manutenção de equipamentos (Souza, 2002). Por outro lado, a IN 51/2002 (Brasil, 2002) preconizava teores mínimos e máximos para a qualidade do leite, que foram ajustados e reeditados pela IN 62 (Brasil, 2011).

A temperatura e o período de armazenamento, que o leite fica submetido nas propriedades, determinam, de maneira seletiva e pronunciada, a intensidade de desenvolvimento das diversas espécies microbianas contaminantes. As temperaturas baixas inibem ou reduzem a multiplicação da maioria das bactérias e diminuem a atividade de enzimas degradativas.

Segundo a IN 62/2011 (Brasil, 2011), o leite cru pode ser refrigerado em tanques de refrigeração por expansão direta (à granel) ou por imersão de latões em água gelada, desde que o leite seja mantido abaixo de $4^{\circ} \mathrm{C}$ e $7^{\circ} \mathrm{C}$, respectivamente, por, no máximo, 48 horas. A refrigeração através de freezer não pode ser mais utilizada. Isto se deve porque 0 resfriamento por freezer não tem a capacidade de auto-agitação, fazendo com que o leite congele nas partes externas, fazendo disso um meio de isolamento para favorecimento do desenvolvimento dos microrganismos. $\mathrm{O}$ congelamento acarreta em perda de qualidade da composição do leite.

Assim, este trabalho teve como objetivo analisar e avaliar a composição, CCS e CBT do leite cru refrigerado de propriedades rurais da região de Marechal Cândido Rondon, com diferentes tipos de refrigeração, e tempos distintos de armazenamento, e métodos de higiene utilizados nas propriedades.

\section{MATERIAL E MÉTODOS}

O trabalho foi realizado na cidade de Marechal Cândido Rondon - PR, em 30 propriedades rurais leiteiras. Foram analisadas 90 amostras de leite cru refrigerado oriundo destas propriedades. Das 90 amostras de leite, 30 amostras foram provenientes de propriedades que possuem leite refrigerado com resfriador à granel (tanque de expansão), 30 que tinham resfriador de imersão (à taro) e 30 com resfriamento através de freezer.

As propriedades foram analisadas por meio de um questionário e por meio de amostras de leite cru, coletadas de seus respectivos resfriadores e analisadas em relação à sua qualidade. O questionário tinha por base perguntas referente ao tipo de resfriamento e sistema de ordenha utilizado, como da higiene aplicada a eles, assim como da alimentação fornecida aos animais. As amostras de leite cru foram coletadas 
quanto ao tempo de armazenamento, que foi de 2 horas, 12 horas e 24 horas.

A caracterização dos

procedimentos de higiene foi avaliada mediante a aplicação do questionário. A avaliação dos métodos de higienização do tanque de refrigeração e dos equipamentos de ordenha encontrados foram definidos como: 1 - Ótima eficácia: uso para limpeza de água quente a $65-70^{\circ} \mathrm{C}$ em conjunto com os detergentes alcalino e ácido a cada ordenha ou intercalado no dia; 2 Eficácia moderada - uso para limpeza de água morna em conjunto com os detergentes alcalino e ácido a cada ordenha ou intercalado no dia; 3 - Baixa eficácia - uso somente de água quente a $65-70^{\circ} \mathrm{C}$ para limpeza, ou somente água morna, e/ou utilização de detergente neutro.

Os sistemas de ordenha encontrados pelo questionário foram: 1 - Sistema de ordenha canalizada; 2 Sistema de ordenha balde ao pé; 3 Sistema de ordenha manual. Para a alimentação dos animais foram encontrados três diferentes tipos de alimentação fornecida aos animais, sendo eles caracterizados como: 1 Somente utilização de pastagem; 2 Utilização de pastagem e fornecimento de concentrado; 3 - Utilização de pastagem e fornecimento de concentrado + forragem conservada (silagem e/ou feno).

Para a determinação da composição do leite, as amostras foram encaminhadas para análise ao Laboratório de Controle de Qualidade do Leite (RBQL), da Associação Paranaense de Criadores de Bovinos da Raça Holandesa, situada na cidade de Curitiba - PR. Foram analisados os teores de gordura, proteína, lactose e sólidos totais do leite em equipamento do tipo Bentley 2000 (Bentley Instruments, 1995a), que são conhecidos como os analisadores rápidos de infravermelho.
Para a análise da contagem total de células somáticas, esta também foi enviada ao Laboratório de Controle de Qualidade do Leite (RBQL), e avaliada através do equipamento Somacount 300 (Bentley Instruments, 1995b), sendo o método utilizado conhecido como citometria de fluxo.

Para análise da Contagem Bacteriana Total, as amostras foram encaminhadas ao laboratório de Microbiologia e Bioquímica da Universidade Estadual do Oeste do Paraná, Campus de Marechal Cândido Rondon - PR. As amostras foram analisadas por meio da contagem em placas. O leite era diluído em tubos de ensaio com água destilada e após pipetados $1,0 \mathrm{ml}$ da diluição em placas de Petri, e semeadas em Ágar Padrão para Contagem (PCA). Após a homogeneização, as placas foram incubadas a $32{ }^{\circ} \mathrm{C}$ por 48 horas. A leitura da placa foi realizada com 0 auxílio de um contador de colônias, e calculado 0 número de unidade formadora de colônias (UFC) de acordo com a diluição utilizada.

O método de contagem de microrganismos em placas é um método geral, que pode ser utilizado para contagem de grandes grupos microbianos, como aeróbios mesófilos, psicrotróficos, termófilos, bolores e leveduras, variando-se o tipo de meio, a temperatura e o tempo de incubação (Hajdenwurcel, 1998; Silva et al., 1997). Os mesófilos incluem um grupo de microrganismos capazes de se multiplicarem numa faixa de temperatura entre 20 e $45^{\circ} \mathrm{C}$, tendo uma temperatura ótima de crescimento a $32^{\circ} \mathrm{C}$ e, portanto, encontrando nas temperaturas ambientes de países de clima tropical, condições ótimas para o seu metabolismo (Franco \& Ladgraf, 2008). É considerado um bom indicador de qualidade microbiológica, sendo a contagem microbiana em placa realizada para se avaliar as condições 
higiênicas na qual 0 produto foi processado (Jay, 1996; Teixeira et al., 1996).

O delineamento experimental utilizado foi 0 completamente casualizado, em arranjo fatorial $3 \times 3$, considerando como fatores os tipos de refrigeração (tanque de expansão, tanque de imersão e freezer) e os tempos de armazenamento (2, 12 e 24 horas). As variáveis dependentes analisadas foram: gordura do leite, proteína do leite, lactose e sólidos totais, contagem de células somáticas (CCS), contagem bacteriana total (CBT), e ainda higienização do tanque de refrigeração e higienização dos equipamentos de ordenha.

As análises estatísticas foram realizadas pelo procedimento modelos lineares gerais (GLM - General Linear Models), sendo as variáveis dependentes submetidas à análise de variância e teste de comparação múltipla, considerando os efeitos do tipo de resfriamento, tempo de armazenamento e interação entre estes. O nível de significância para rejeição da hipótese de nulidade foi de 0,05.

\section{RESULTADOS E DISCUSSÃO}

Os dados obtidos através do questionário evidenciaram que $70 \%$ dos produtores possuíam sistema de ordenha balde ao pé, 13,33\% possuíam sistema de ordenha canalizada e, $16,67 \%$ dos produtores utilizavam ainda o sistema de ordenha manual, acarretando um provável meio de contaminação do leite, se as mãos do ordenhador não estiverem limpas e higienizadas.

Em relação à limpeza dos equipamentos de ordenha, foi observado que todos os produtores realizavam a limpeza diariamente. Os métodos utilizados para a limpeza dos equipamentos de ordenha encontrados foram: $50 \%$ dos produtores para água quente (temperatura entre 65 e $70^{\circ} \mathrm{C}$ ) em conjunto com a utilização de detergente alcalino e ácido; 26,67\% utilizavam detergente alcalino e ácido em água morna; $20 \%$ utilizavam outra forma de limpeza, ou somente água morna, ou em conjunto com detergentes comuns; e somente água quente como forma de limpeza, 3,33\% dos produtores.

Para a limpeza do tanque de resfriamento os resultados obtidos mostraram que $56,66 \%$ dos produtores utilizavam detergente alcalino e ácido na limpeza, porém com água morna; $36,67 \%$ dos produtores utilizavam em conjunto água quente $e$ detergente alcalino e ácido na limpeza do tanque, e $6,67 \%$ dos produtores utilizavam como forma de limpeza somente água quente sem o uso de detergentes específicos.

Outro método para diminuir a probabilidade de contaminação no leite, é fazendo-se a desinfecção da sala de ordenha periodicamente e, para isto foi observado que $70 \%$ dos produtores não faziam nenhum tipo de desinfecção da sala de ordenha, $10 \%$ dos produtores faziam a desinfecção uma vez ao ano, $13,33 \%$ dos produtores faziam a desinfecção duas vezes ao ano, e somente $6,67 \%$ dos produtores faziam a desinfecção da sala de ordenha mensalmente.

Para o total das 90 amostras analisadas, verificou-se que $74,44 \%$ das amostras estavam fora dos padrões exigidos pela IN 62/2011 em, pelo menos, uma característica. Para os teores de gordura e sólidos totais, verificou-se abaixo do limite mínimo permitido, 7,78 e 3,33\% das amostras, respectivamente. Em relação à CCS e a CBT houve acima do limite máximo permitido, 58,89 e $50,00 \%$ das amostras, respectivamente. Para o teor de proteína não foram encontradas amostras fora dos padrões exigidos pela normativa. De acordo com BRASIL (2011), o teor mínimo de proteína, 
gordura e sólidos totais deve ser de 2,9; 3,0 e $11,4 \%$, respectivamente. A legislação brasileira não estipula valores mínimos para o teor de lactose.

Para os tipos de resfriamento, tanque de expansão, tanque de imersão e, resfriamento em freezer, os teores médios de gordura foram 3,$76 ; 3,88$ e $3,65 \%$ respectivamente. $O$ teor de proteína encontrado para os tipos de resfriamento tanque de expansão, tanque de imersão e freezer foi de 3,22; 3,17 e $3,21 \%$, respectivamente. Os teores de lactose encontrados neste estudo foram de 4,$42 ; 4,35$ e $4,38 \%$, para os respectivos tipos de resfriamento, tanque de expansão, tanque de imersão, e freezer. Os teores médios de sólidos totais observados foram de 12,30; 12,30 e 12,12\%, em relação aos tipos de resfriamento, tanque de expansão, tanque de imersão e freezer, respectivamente.

Para os tempos de armazenamento de 2, 12 e 24 horas os valores médios encontrados para a gordura foram de 3,$79 ; 3,74$ e $3,76 \%$, respectivamente. Para o teor proteína foram obtidos valores de 3,19; 3,21 e $3,20 \%$, para os respectivos tempos de armazenamento de 2, 12 e 24 horas. Para o teor de lactose, nos tempos de armazenamento de 2, 12 e 24 horas observaram-se que os valores médios foram de 4,39; 4,38 e 4,38\%, respectivamente. Os teores médios de sólidos totais encontrados para os tempos de armazenamento de 2, 12 e 24 horas foram de 12,26; 12,23 e $12,23 \%$, respectivamente.

De acordo com os valores obtidos, verificou-se que a composição do leite, para os componentes gordura, proteína, lactose e sólidos totais, em relação aos tipos de resfriamento, não apresentou diferença significativa $(P>0,05)$ pelo teste de Tukey. O componente lactose variou significativamente a $(P<0,10)$ para o tanque de expansão em relação ao tanque de imersão. Dessa maneira, pode-se verificar que os valores médios das amostras de leite para os tipos de resfriamento estão dentro dos padrões mínimos previstos na Instrução Normativa 62 (Brasil, 2011).

Os componentes do leite, gordura, proteína, lactose e sólidos totais não diferiram significativamente $(P>0,05)$, para os tempos de armazenamento do leite em 2, 12 e 24 horas. Assim, não havendo variação nos componentes do leite durante o tempo de estocagem nos tanques, pode-se verificar que os métodos de resfriamento foram eficazes em manter a composição do leite.

Santos et al. (2008) para os tempos de armazenamento de zero, 24, 48 e 72 horas, teores médios de gordura de 3,$79 ; 4,07 ; 3,81$ e $3,82 \%$, respectivamente, e teores de proteína de 3,$22 ; 3,25 ; 3,22$ e 3,23\% nos respectivos tempos de armazenamento e, teores médios de lactose de 4,41; 4,$41 ; 4,39$ e $4,37 \%$, respectivamente, sendo estes resultados semelhantes aos deste estudo.

Gonzalez et al. (2004) quando avaliaram a composição do leite em diferentes meses do ano em Pelotas, encontraram valores de 3,$69 ; 3,15 ; 4,44$ e $12,20 \%$ para os respectivos teores de gordura, proteína, lactose e sólidos totais. Reis et al. (2007) observaram valores médios inferiores para o teor de sólidos totais, em diferentes tipos de ordenha, sendo os respectivos valores de 11,11 e $11,84 \%$.

Para os tempos de armazenamento de 2, 12 e 24 horas os valores médios encontrados para a CCS foram de $8,80 \times 10^{5}, 8,60 \times 10^{5}$ e $8,79 x$ $10^{5} \mathrm{CS} / \mathrm{mL}$, respectivamente, e foram de $7,18 \times 10^{5}, 7,86 \times 10^{5}$ e $1,11 \times 10^{6}$ $\mathrm{CS} / \mathrm{mL}$ para os respectivos tipos de refrigeração tanque de expansão, freezer e tanque de imersão. A CBT nos diferentes tipos de refrigeração foi de $2,33 \times 10^{5}, 1,19 \times 10^{6}$, e $1,26 \times 10^{6}$ UFC/mL para o tanque de expansão, tanque de imersão e freezer, 
respectivamente. Nos tempos de armazenamento de 2, 12, e 24 horas os respectivos resultados encontrados foram de $4,11 \times 10^{5}, 7,33 \times 10^{5}$, e $1,16 \times$ $10^{6} \mathrm{UFC} / \mathrm{mL}$.

Para a CCS não houve diferença significativa $\quad(P>0,05)$ para 0 resfriamento utilizando-se freezer em relação ao tanque de expansão, e ao tanque de imersão. No entanto, verificou-se diferença significativa $(P<0,05)$ entre o tipo de refrigeração tanque de expansão e o tipo tanque de imersão para a CCS. Para CBT, verificou-se que houve diferença significativa $(P<0,05)$ entre os tipos de refrigeração, sendo que o tanque de expansão diferiu-se do tanque de imersão e freezer.

Não houve diferença significativa $(P>0,05)$ para a CCS em função dos tempos de armazenamento, entretanto, para a CBT, verificou-se que houve diferença significativa $(P<0,05)$ entre os tempos de armazenamento, sendo que o tempo de 2 horas diferenciou-se dos tempos de 12 e 24 horas. A partir dos dados obtidos verifica-se que os tipos de refrigeração tanque de imersão e freezer, como o tempo de armazenamento 12 e 24 horas não foram eficazes em manter a qualidade do leite. Dessa maneira, observa-se ainda que apenas os valores médios para CBT, do tanque de expansão e do tempo de armazenamento de 2 horas, apresentam-se nos padrões exigidos pela IN 62 (Brasil, 2011).

Relaciona-se a qualidade do leite com a Contagem Bacteriana Total (CBT) do leite cru, que é o teste empregado para avaliação da qualidade microbiológica do leite. O resultado do teste fornece indicação dos cuidados de higiene empregados na obtenção e no manuseio do leite na fazenda. Altas contagens de bactérias totais indicam falhas na limpeza dos equipamentos, na higiene da ordenha e/ou problemas na refrigeração do leite.
Outro indicador decisivo na qualidade do leite é a Contagem de Células Somáticas (CCS). Para Coldebella (2004), o fator mais importante que afeta a contagem de células somáticas e, consequentemente, as perdas econômicas da cadeia produtiva do leite, é a mastite bovina, inflamação da glândula mamária.

Gonzalez et al. (2004) encontraram variação na CCS em diferentes sistemas de produção, observando valores para sistema nãoespecializado de $9,07 \times 10^{5} \mathrm{CS} / \mathrm{mL}$, semi-especializado de $4,37 \times 10^{5}$ $\mathrm{CS} / \mathrm{mL}$, e especializado de $2,61 \times 10^{5}$ $\mathrm{CS} / \mathrm{mL}$.

Arcuri et al. (2006) encontraram para a contagem de bactérias mesófilas (contagem padrão - CBT) valores médios variando de $4,2 \times 10^{3}$ até $4,14 \times$ $10^{6} \mathrm{UFC} / \mathrm{mL}$, verificando assim que $79 \%$ dos rebanhos atenderiam ao padrão. Rosa \& Queiroz (2007) constataram que $80,0 \%$ das amostras de leite cru e resfriado analisadas apresentavam contagens de microrganismos aeróbios mesófilos acima do limite estabelecido.

Para tempos de armazenamento de zero, 24, 48 e 72 horas, Santos et al. (2008) verificaram, em tanques de expansão, resultados da CCS de 5,26 x $10^{5} ; 5,27 \times 10^{5} ; 4,07 \times 10^{5}$ e $4,11 \times 10^{5}$ $\mathrm{CS} / \mathrm{mL}$, respectivamente, e para a CBT valores de $5,3 \times 10^{6} ; 9,8 \times 10^{5} ; 2,5 \times 10^{6}$ e 4,3 $\times 10^{6} \mathrm{UFC} / \mathrm{mL}$, respectivamente.

De acordo com Pinto et al. (2006), a refrigeração do leite cru por períodos prolongados, na fonte de produção ou na indústria, pode comprometer a sua qualidade.

Não foi verificada interação significativa entre os tipos e tempos de resfriamento. No entanto, por meio dos dados obtidos a partir do questionário, foram realizadas interações, para avaliar os métodos de higiene aplicados nas propriedades pesquisadas, como dos sistemas de ordenha encontrados, em relação à CCS e CBT do leite nos tipos 
de refrigeração. Foi também avaliado os tipos de alimentação encontrados em relação aos componentes gordura e proteína do leite. Outras interações não foram possíveis de serem feitas, devido aos dados coletados através do questionário, não estarem dispostos igualmente entre si.

De acordo com a análise de variância (Tabela 1), o teor de gordura do leite não apresentou diferença significativa pelo teste $\mathrm{F}$ ao nível de $5 \%$ de probabilidade, em relação aos tipos de alimentação fornecido aos animais. $\mathrm{O}$ teor de gordura para a alimentação utilizando somente pastagem foi de $3,56 \%$, para pastagem+concentrado foi de 3,78 e para a alimentação com pastagem+concentrado+forragem conservada foi de 3,87 .

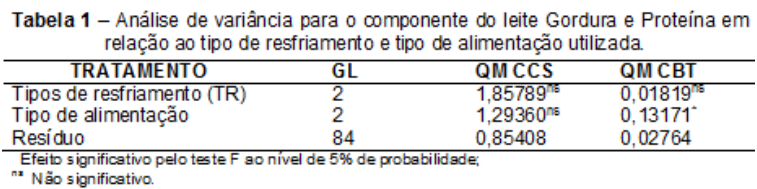

Houve diferença significativa pela análise de variância (Tabela 1) para 0 componente proteína do leite em relação aos tipos de alimentação fornecido. Pelo teste de Tukey, foi verificado que a alimentação que utilizava

pastagem+concentrado+forragem conservada o teor de proteína do leite foi de $3,22 \%$ e este diferiu significativamente $\quad(p>0,05) \quad d a$ alimentação somente com pastagem, que teve um teor de proteína de 3,01\%. O teor de proteína do leite para a alimentação com a utilização de pastagem+concentrado foi de $3,11 \%$ e este não apresentou diferença significativa $(p>0,05)$ em relação aos outros tipos de alimentação.

A ingestão de energia é o principal fator nutricional relacionado ao teor e a produção de proteína do leite. O aumento da ingestão de energia através de fontes de carboidratos aumenta a produção e a porcentagem de proteína através do leite (PERES, 2001).

De acordo com a análise de variância (Tabela 2) não foi observado diferença significativa pelo teste $\mathrm{F}$ ao nível de $5 \%$ de probabilidade para a CCS e CBT em relação aos sistemas de ordenha. Para a interação tipos de resfriamento $\mathrm{x}$ sistemas de ordenha foi verificado diferença significativa em relação a CCS e CBT.

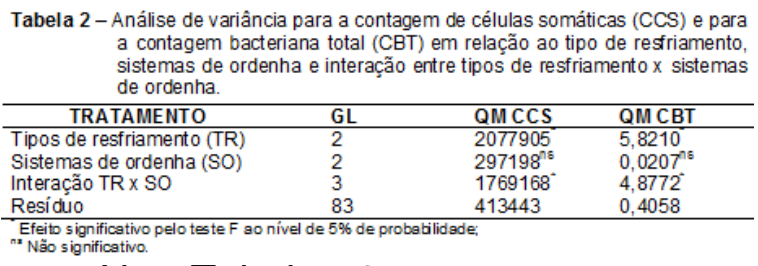

$\mathrm{Na}$ Tabela 3 encontram-se os valores médios da CCS para a interação tipos de resfriamento em relação aos sistemas de ordenha.

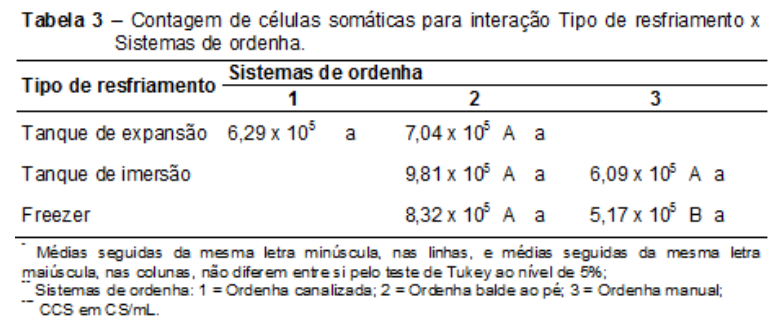

Para os valores médios de CCS, verifica-se pela Tabela 3 que entre os sistemas de ordenha encontrados, não houve diferença significativa $(P>0,05)$ Quando comparados os sistemas de ordenha com os tipos de resfriamento, verifica-se no sistema de ordenha manual diferença significativa $(P<0,05)$ entre 0 tanque de imersão e 0 resfriamento por freezer. Para o sistema de ordenha balde ao pé não houve diferença significativa entre os tipos de resfriamento. No sistema de ordenha canalizada foram encontradas propriedades que possuíam somente resfriamento pelo tanque de expansão, e para o sistema de ordenha manual não foram encontradas propriedades com resfriamento por tanque de expansão.

$\mathrm{Na}$ Tabela 4 encontram-se os valores médios da CBT para a interação 
tipos de resfriamento em relação aos sistemas de ordenha.

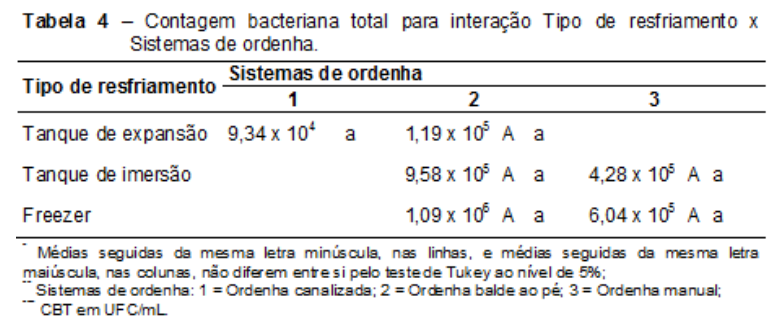

Para os valores médios de CBT, verifica-se pela Tabela 4 que entre os sistemas de ordenha encontrados, não houve diferença significativa $(P>0,05)$. Quando comparados os sistemas de ordenha com os tipos de resfriamento, verifica-se que não houve diferença significativa $(P>0,05)$ para $o$ tanque de expansão, tanque de imersão e freezer.

De acordo com a análise de variância (Tabela 5) foi observado diferença significativa pelo teste $F$ ao nível de $5 \%$ de probabilidade para a CCS em relação à higiene do tanque de armazenamento, e para a interação tipos de resfriamento $x$ higiene do tanque de armazenamento. Para a CBT houve diferença significativa apenas para a interação.

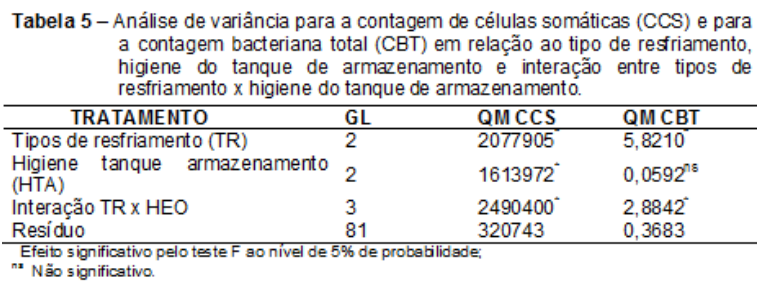

$\mathrm{Na}$ Tabela 6 encontram-se os valores médios da CBT para a interação tipo de resfriamento em relação à higiene aplicada ao tanque de armazenamento.

Tabela 6 - Contagem bacteriana total para interação Tipo de resfriamento $x$ Higiene do tanque de armazenamento.

Tipo de resfriamento $\frac{\text { Higiene do tanque de ammazen amento }}{1}$

Tanque de expansão $6,79 \times 10^{4} \mathrm{~B}$ a $\quad 3,23 \times 10^{5} \mathrm{~B}$ a $6,16 \times 10^{5} \mathrm{~A}$ a

Tanque de imersão $\quad 1,07 \times 10^{6} \mathrm{~A}$ a $2,63 \times 10^{6} \mathrm{~A}$ a $5,13 \times 10^{6} \mathrm{~A}$ a

Freezer $\quad 3,02 \times 10^{6} \mathrm{~A}$ a $\quad 5,13 \times 10^{5} \mathrm{AB}$ a

Médias seguidas da mesma letra minúscula, nas linhas, e médias seguidas da mesma letra

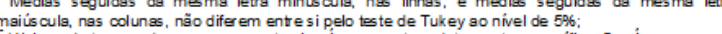
Higiene do tanque de armazenamento: 1 = Água querte + detergente es pecífico; 2 = Água morna detergente especifico; 3 = Outros métodos:

Verifica-se pelos valores da Tabela 6 que entre os métodos utilizados para higiene do tanque de armazenamento não houve diferença significativa $(P>0,05)$ para a $C B T$. O método de água quente + detergente específico quando comparado em relação aos tipos de resfriamento apresentou diferença significativa $(P<0,05)$, sendo que o tanque de expansão diferiu do tanque de imersão e freezer. Para o método água morna + detergente específico verificou que o resfriamento por freezer não diferiu dos demais tipos de resfriamento, no entanto verificou que o tipo tanque de expansão diferiu significativamente do tanque de imersão. Quando da utilização de outros métodos de limpeza, estes não diferiram entre os tipos de resfriamento.

Santana et al. (2001) verificaram que uma das principais fontes de microorganismos mesófilos e psicrotróficos no processo de produção do leite foi a água residual dos equipamentos. Os tanques de expansão e os latões foram os principais pontos de contaminação, tanto pelas altas contagens, como pelo volume de água residual. Quanto aos tanques de expansão, as contagens de mesófilos da água residual foram altas nas propriedades onde a higienização foi manual e menores na propriedade onde a higienização é automatizada.

Silva et al. (2011) verificaram, com exceção em uma propriedade, que em nenhuma propriedade a água era tratada, constituindo a inexistência de tratamento da água como possível fator para a contaminação de utensílios e equipamentos de ordenha, comprometendo assim, a qualidade do leite.

$\mathrm{Na}$ Tabela 7 encontram-se os valores médios da CCS para a interação tipo de resfriamento em relação à higiene aplicada ao tanque de armazenamento. 


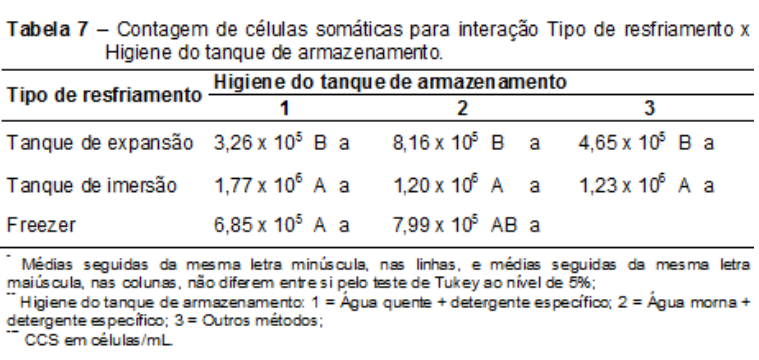

Para os valores médios de CCS, verifica-se pela Tabela 7 que entre os métodos utilizados para higiene do tanque de armazenamento, não houve diferença significativa $(P>0,05)$. Quando comparados os métodos de higiene com os tipos de resfriamento, verifica-se para o método de água quente + detergente específico diferença significativa $(P<0,05)$ entre o tanque de expansão em relação aos outros tipos de resfriamento. Verifica-se para o método de água morna + detergente específico diferença entre o tanque de expansão e o tanque de imersão, porém 0 resfriamento por freezer não diferiu dos demais tipos de resfriamento. Para a utilização de outros métodos de higiene, diferiu significativamente $(P<0,05) \quad 0$ tanque de expansão para o tanque de imersão.

De acordo com a análise de variância (Tabela 8) não se verificou diferença significativa pelo teste $F$ ao nível de $5 \%$ de probabilidade para a variável CCS em relação à higiene dos equipamentos de ordenha, e para a interação tipos de resfriamento $\mathrm{x}$ higiene dos equipamentos de ordenha.

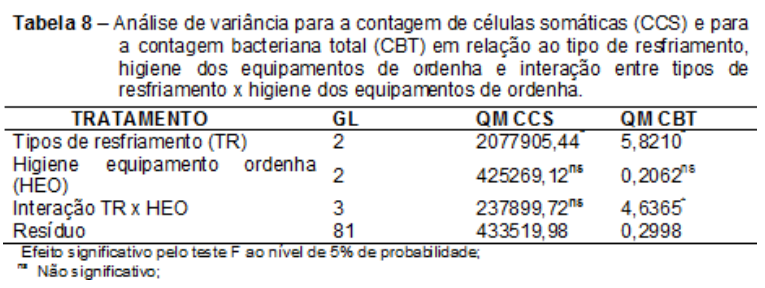

$\mathrm{Na}$ Tabela 9 encontram-se os valores médios da CBT para a interação tipo de resfriamento em relação à higiene aplicada aos equipamentos de ordenha.
Tabela 9 - Contagem bacteriana para interação Tipo de resfriamento $\mathrm{x}$ higiene dos equipamentos de ordenha.

Tanque de resfriamento $\frac{\text { Higiene de equipamentos de ordenha }}{1}$

Tanque de expansão $\quad 1,66 \times 10^{5} \mathrm{~B}$ a $\quad 8,91 \times 10^{5} \mathrm{~A}$ a $\quad 4,57 \times 10^{5} \mathrm{~B}$ b

Tanque de imersão $\quad 2,29 \times 10^{6} \mathrm{~A}$ a $2,14 \times 10^{6} \mathrm{~A}$ a $\quad 5,37 \times 10^{6} \mathrm{~A}$ a

Freezer

$2,88 \times 10^{6} \mathrm{~A}$ a $3,24 \times 10^{5} \mathrm{~A}$ b

Médias seguidas da mesma letra minísculs, nas linhas, e médias seguidas da mesma letra
maísculs, nas colunas, năo diferem entre si pelo teste de Tukey ao nivel de 596 ; Higiene dos equipamentos de oddenha: 1 = Água quente + detergente específico; 2 = Água morna detergente especifico; $3=$ Outros métodos

Verifica-se pelos valores da Tabela 9 que entre os métodos utilizados para higiene dos equipamentos de ordenha houve diferença significativa $(P<0,05)$ para a CBT. Para o tanque de expansão verifica que a higiene através de outros métodos diferiu dos métodos de água quente e água morna em conjunto com o detergente específico. Para 0 resfriamento por freezer o método de água morna + detergente específico diferiu do método de água quente. No tanque de imersão não houve divergências.

O método de água quente + detergente específico quando comparado em relação aos tipos de resfriamento apresentou diferença significativa $(P<0,05)$, sendo que 0 tanque de expansão diferiu do tanque de imersão e freezer. Para o método água morna + detergente específico verificou que os tipos de resfriamento não apresentaram diferença entre eles. Para a utilização de outros métodos de higiene, diferiu significativamente $(P<0,05)$ o tanque de expansão para 0 tanque de imersão.

Silva et al. (2011) verificaram que os equipamentos e principalmente utensílios de ordenha como baldes e latões apresentaram altas contagens microbianas, o que indicou a existência de falhas nos procedimentos de higienização.

Segundo estudo feito por Vallin et al. (2009), estes verificaram que a maior eficiência das práticas de higiene na ordenha foi obtida em propriedades com ordenha mecânica e refrigeração em tanque de expansão, onde a redução chegou a 93,95\%. Nas propriedades onde Fagan et al. (2005) aplicaram 
essas mesmas práticas houve uma redução média de $99,2 \%$ na CBT do leite.

Santana et al. (2001) verificaram que a prática de utilizar água aquecida a aproximadamente $100^{\circ} \mathrm{C}$ para higienização das teteiras, resultou em menores contagens iniciais de mesófilos e psicrotróficos.

Fonseca e Santos (2000) consideram que $95 \%$ dos problemas de altas contagens de bactérias no leite são originários da deficiência nos procedimentos de higienização e manejo dos utensílios e equipamentos de ordenha.

Observa-se através dos dados obtidos que o melhor método de refrigeração verificado foi o tanque de expansão, no entanto a utilização do tanque de imersão é permitida pela IN 62. Verifica-se falta de controle e fiscalização pelos laticínios e órgãos governamentais, pois muitas propriedades ainda utilizam 0 resfriamento por freezer, o que pela legislação é proibido.

\section{CONCLUSÃO}

Para a CCS e CBT a maioria dos valores médios observados encontra-se acima dos limites máximos permitidos. Houve diferença significativa para a CCS e CBT em relação aos tipos de refrigeração, e para os tempos de armazenamento diferiu significativamente a CBT, não havendo diferença para a CCS. Pelos resultados das análises de composição pode-se afirmar que os métodos de resfriamento foram eficazes, e o tempo de armazenamento não afetou a qualidade destes componentes. Em relação à CCS e CBT pode-se afirmar que os métodos de resfriamento não foram totalmente eficazes, e que o tempo de armazenamento a que o leite fica submetido nas propriedades pode acarretar diminuição da sua qualidade, como dos métodos de higienização empregados no processo da produção leiteira.

\section{REFERÊNCIAS}

ARCURI, E.F.; BRITO, M.A.V.; BRITO, J.R.F. et al. Qualidade microbiológica do leite refrigerado nas fazendas. Arquivo Bras de Med Vet e Zootecnia, v.58, n.3, p.440-446, 2006.

BENTLEY INSTRUMENTS. Bentley 2000: operator's manual. Chaska, 1995a. 77p.

BENTLEY INSTRUMENTS. Somacount 300: operator's manual. Chaska, 1995b. 12p.

BRASIL. Ministério da Agricultura, Pecuária e Abastecimento. Instrução Normativa n. 51, de 18 de Setembro de 2002. Regulamentos Técnicos de Produção, Identidade, Qualidade, Coleta e Transporte do Leite. Diário Oficial da União. Brasília, DF: Ministério da Agricultura, Departamento de Inspeção de Produtos de Origem Anima, 2002, 39p. Instrução Normativa n. 51, 2002.

BRASIL. Ministério da Agricultura, Pecuária e Abastecimento. Regulamento Técnico de Identidade e Qualidade do Leite Cru Refrigerado. In: BRASIL. Ministério da Agricultura, Pecuária e Abastecimento. Instrução Normativa no 62, de 29 de dezembro de 2011. Diário Oficial da União, 29 dez. 2011. Seção 1, p.13-14, 2011.

BRITO, M.A.V.P.; BRITO, J.R.F.; PORTUGAL, J.A.B. Identificação de contaminantes bacterianos no leite cru de tanques de refrigeração. Revista do Instituto de Laticínios Cândido Tostes, v.57, p.47-52, 1998.

COLDEBELLA, A.; MACHADO, P.F.; DEMÉTRIO, C.G.B. et al. Contagem de células somáticas e produção de leite em vacas holandesas confinadas. Revista Brasileira de Zootecnia, v.33, n.3, p.623-634, 2004.

FAGAN, E.P.; BELOTI, V.; BARROS, M.F. et al. Evaluation and implementation of good pratices in main points of microbiological contamination in milk production. SEMINA: Ciências Agrárias, v.26, n.1, p.83-92, 2005.

FONSECA, L.F.L.; SANTOS, M.V. Qualidade e controle de mastite. São Paulo: Lemos Ed. e Graf. 2000.175p. 
FRANCO, B.D.G.M.; LANDGRAF, M. Microbiologia dos alimentos. São Paulo: Atheneu, $2^{\mathrm{a}}$ ed., 2008.

GONZALEZ, H.L.; FISCHER, V.; RIBEIRO, M.E.R. et al. Avaliação da qualidade do leite na bacia leiteira de Pelotas, RS. Efeito dos meses do ano. Revista Brasileira de Zootecnia, v.33, n.6, p.1531-1543, 2004.

HAJDENWURCEL, J.R. Atlas de microbiologia de alimentos. São Paulo: Fonte Comunicações e Editora, 1998. 66p.

JAY, J.M. Modern food microbiology. 5.ed. New York: Champan and Hall, 1996. 661p.

MINIM, L.A.; COIMBRA, J.S.R.; MINIM, V.P.R. Influence of Temperature and Water and Fat Contents on the Thermophysical Properties of Milk. Journal of Chemical and Engineering Data, v.47, p.1488-1491, 2002.

PERES, J.R. O leite como ferramenta do monitoramento nutricional. In: GONZALEZ, F.H.D. et al. Uso do leite para monitorar a nutrição e metabolismo de vacas leiteiras. Porto Alegre: Universidade Federal do Rio Grande do Sul, 2001. p.30-45.

PINTO, C.L.O.; MARTINS, M.L.; VANETTI, M.C.D. Qualidade microbiológica de leite cru refrigerado e isolamento de bactérias psicrotróficas proteolíticas. Ciência e Tecnologia de Alimentos, v.26, n.3, p.645-651, 2006.

REIS, G.L.; ALVES, A.A.; LANA, A.M.Q. et al. Procedimentos de coleta de leite cru individual e sua relação com a composição físico-química e a contagem de células somáticas. Ciência Rural, v.37, n.4, p.1134-1138, 2007.

ROSA, L.S.; QUEIROZ, M.I. Avaliação da qualidade do leite cru e resfriado mediante a aplicação de princípios do APPC. Ciência e Tecnologia de Alimentos, v.27, n.2, p.422-430, 2007.

SANTANA, E.H.W.; BELOTI, V.; BARROS, M.A.F. et al. Milk contaminação do leite em diferentes pontos do processo de produção: I Microrganismos aeróbios mesófilos e psicrotróficos. SEMINA: Ciências Agrárias, v.22, n.2, p.145-154, 2001.

SANTOS, P.A.; SILVA, M.A.P.; ANASTÁCIO, P.I.B. et al. Qualidade do leite cru refrigerado estocado por diferentes períodos. Revista do
Instituto de Laticínios Cândido Tostes, v. 63, n. 5, p. 36-41, 2008.

SILVA, N.; JUNQUEIRA, V.C.A.; SILVEIRA, N.F.A. Manual de métodos de análise microbiológica de alimentos. São Paulo: Varela, 1997. 295p.

SILVA, L.C.C.; BELOTI, V.; TAMANINI, R. et al. Rastreamento de fontes da contaminação microbiológica do leite cru durante a ordenha em propriedades leiteiras do Agreste Pernambucano. SEMINA: Ciências Agrárias, v.32, n.1, p.267-276, 2011.

SOUZA, L.J. Nova Legislação Comentada de Produtos Lácteos - Revisada e Ampliada, Revisão Técnica. Revista Indústria de Laticínios, 327p., 2002.

VALLIN, V.M.; BELOTI, V.; BATTAGLINI, A.P.P et al. Melhoria da qualidade do leite a partir da implantação de boas práticas de higiene na ordenha em 19 municípios da região central do Paraná. SEMINA: Ciências Agrárias, v.30, n.1, p.181-188, 2009.

TEIXEIRA, A.M.; MASSAGUER, P.R.; FERREIRA, E.C. et al. Agilizando a contagem de bactérias em leite cru brasileiro. Revista Indústria de Laticínios, v.4, n.25, p.46-49, 2000. 